\title{
High-Performance Thin-Layer Chromatographic Quantification of Rosmarinic Acid and Rutin in Abnormal Savda Munziq
}

\author{
S. G. Tian, ${ }^{1,2}$ L. D. Xin, ${ }^{1,2}$ and Halmuart Upur' \\ ${ }^{1}$ Xinjiang Key Laboratory of Famous Prescription and Science of Formulas, Xinjiang, Urumqi 830011, China \\ ${ }^{2}$ College of TCM, Xinjiang Medical University, Xinjiang, Urumqi 830011, China \\ Correspondence should be addressed to Halmuart Upur; tsgyz@sina.com
}

Received 16 January 2012; Revised 4 June 2012; Accepted 19 June 2012

Academic Editor: Sevgi Kolayli

Copyright (c) 2013 S. G. Tian et al. This is an open access article distributed under the Creative Commons Attribution License, which permits unrestricted use, distribution, and reproduction in any medium, provided the original work is properly cited.

\begin{abstract}
A high-performance thin-layer chromatographic (HPTLC) method has been established for simultaneous analysis of rosmarinic acid and rutin in Abnormal Savda Munziq (ASMq). A methanol extract of ASMq was used for quantification. The compounds were separated on silica gel $\mathrm{H}$ thin layer plate with ethyl acetate-formic acid-acetic acid-water $15: 1: 1: 1.5$ (v/v) as a developer, trichloroethanol as the color reagent. The plates were scanned at $365 \mathrm{~nm}$. The linear calibration data of rosmarinic acid and rutin were in the range of 0.0508 to $0.2540 \mu \mathrm{g}(r=0.9964), 0.2707$ to $1.35354 \mu \mathrm{g}(r=0.9981)$, respectively. The recovery rate of rosmarinic acid was $99.17 \%(\mathrm{RSD}=2.92 \%)$ and rutin was $95.24 \%(\mathrm{RSD}=2.38 \%)$. The method enables rapid screening, precise, selective, and sensitive quantification for pharmaceutical analysis.
\end{abstract}

\section{Introduction}

Abnormal Savda Munziq (ASMq), one of the Uighur medicinal herbal preparations, is made up of ten medicinal species, which are Cordia dichotoma Forst. f., Anchusa italica Retz., Glycyrrhiza uralensis Fisch., Adiantum capillus-veneris L., Euphorbia humifusa Willd., Ziziphus jujuba Mill., Lavandula angustifolia Mill., Foeniculum vulgare Mill., Melissa officinalis L., and Alhagi pseudalhagi Desv. These herbs are widely distributed in the Xinjiang region of China. ASMq has long been used in Traditional Uighur Medicine for the treatment of several diseases such as digestive cancer, diabetes, cardiovascular diseases or chronic asthma [1], the effects on nonspecific immunity, humeral immunity, and cell immunity functions of cyclophosphamide-induced immune-suppressed mice [2] . It is regularly used by Uighur physicians for the treatment of cancer, and in southern Xinjiang many ordinary people regularly self-medicate with it to prevent cancers. To date, these putative anticancer effects of ASMq have been little studied and its potential mechanism of action is still unclear. A possible anticancer effect of ASMq clearly warrants further investigation. In previous studies, ASMq was proved to possess strong free radical scavenging effects, decrease biological markers of oxidative stress in man [3], protect mitochondria and DNA against $\mathrm{OH}$-induced oxidative damage in a cellfree system [3,4], and inhibit cancer cells proliferation and viability in vitro [5].

Rutin [6] $\left(\mathrm{C}_{27} \mathrm{H}_{30} \mathrm{O}_{16}\right.$; Figure 1) is a kind of flavonoids, which is found in the Labiatae, Scrophulariaceae, Compositae, and other plants. Rutin has been reported to have antidiabetic, antithrombotic, anti-inflammatory, and anticarcinogenic activities [7]. The literature determined rutin in flavanoidal fraction of stem extract of Hibiscus micranthus (FFHM) by HPTLC [8]. Rosmarinic acid [9] $\left(\mathrm{C}_{18} \mathrm{H}_{16} \mathrm{O}_{8}\right.$; Figure 2) has antioxidant, anti-inflammatory, and antimicrobial activities. The antioxidant activity of rosmarinic acid was found to be stronger than vitamin E. Rosmarinic acid helps to prevent cell damage caused by free radicals, thereby reducing the risk for cancer and atherosclerosis. Rosmarinic acid is also used for food preservation. In Japan the perilla extracts, rich in rosmarinic acid, are used in garnish and improve the shelf life of fresh seafood. Besides, rosmarinic acid is used to treat peptic ulcers, arthritis, cataract, cancer, rheumatoid arthritis, and bronchial asthma as discussed elsewhere [10].

Different analytical methods for the determination of rutin and rosmarinic acid have been reported, which include high-performance liquid chromatography (HPLC) with UV 
<smiles>C[C@@H]1O[C@H](OC[C@H]2O[C@@H](Oc3c(-c4ccc(O)c(O)c4)oc4cc(O)cc(O)c4c3=O)[C@H](O)[C@H](O)[C@@H]2O)[C@H](O)[C@@H](O)[C@@H]1O</smiles>

FIgURE 1: Chemical structure of rutin.<smiles>O=C(/C=C\c1ccc(O)c(O)c1)OCC(C(=O)O)c1ccc(O)c(O)c1</smiles>

Figure 2: Chemical structure of rosmarinic acid.

detection (HPLC-UV) $[11,12]$. At present, the researches on ASMq mainly have focused on its pharmacological actionimmunity [1-5], immunity functions [2, 13], and extraction technology [14]. However, there is little study on simultaneous quantitative analysis of rutin and rosmarinic acid with validated high-performance thin-layer chromatographic (HPTLC) in the pharmaceutical dosage form. The objective of the present work is to develop a simple, economical, precise, and accurate HPTLC method for simultaneous quantitation of rutin and rosmarinic acid in ASMq.

\section{Experimental}

2.1. Chemicals and Materials. Rutin standard was purchased from China Pharmaceutical and Biological Products, 100080, $\geq 92.5 \%$; rosmarinic acid standard was purchased from Sigma-Aldrich, CFAE-536954, $\geq 97.00 \%$.

Methanol used was of HPLC grade (Fisher Chem Alert Guide, USA); ethyl acetate (Fuyu Fine Chemical Company, China), formic acid (Beijing Fine Chemical Company, China) and acetic acid (Nanda Chemical Company, China) used were of analytical grade. Ultrapure water was obtained by a direct-Q system (Millipore, USA). Abnormal Savda Munziq (ASMq) was supplied by Uygur Medicine Department of Xinjiang Medical University. Silica gel H plates $(10 \mathrm{~cm} \times 20 \mathrm{~cm})$, purchased from Huoshan Chemical material factory, China.

CAMAG Linomat 5, CAMAG TLC Scanner 3 was purchased from KAMA GmbH, Switzerland; Milli-Q3 Ultrapure Water Purification Systems purchased from Millipore, USA; Electronic balance with XS105 and AL204 (purchased from Mettler Toledo, Switzerland; Ultrasonic cleaning machine
KQ-200KDE purchased from Kunshan Ultrasonic Instruments Co., Ltd., China, vacuum oven DZF-6021 were purchased from precision equipment Co., Ltd., China.

2.2. Preparation of Standard Solution. Stock solutions of rutin $\left(0.88 \mathrm{mg} \cdot \mathrm{mL}^{-1}\right)$ and rosmarinic acid $\left(6.6 \mathrm{mg} \cdot \mathrm{mL}^{-1}\right)$ were prepared in methanol. Standard solutions of rutin $100 \mu \mathrm{L}$ and rosmarinic acid $25 \mu \mathrm{L}$ were mixed with $200 \mu \mathrm{L}$ methanol and filtered through $0.45 \mu \mathrm{m}$ filter paper, which were then used for subsequent chromatographic analysis.

ASMq was weighed accurately $(2.0000 \mathrm{~g})$ then transferred to a flask and appropriate amount of methanol was added and sonicated $(150 \mathrm{w}, 60 \mathrm{~Hz})$ for $30 \mathrm{~min}$ at room temperature then filtered. Methanol was added to residue and sonicated $(150 \mathrm{w}$, $60 \mathrm{~Hz}$ ) for $40 \mathrm{~min}$. Filtrates were combined and filtered through $0.45 \mu \mathrm{m}$ filter paper. The solvent was evaporated to dryness. Then the residue was dissolved in methanol and diluted to $25 \mathrm{~mL}$ with methanol to obtain a stock solution.

2.3. Chromatography. HPTLC was performed on silica gel $\mathrm{H}$ plates, which were activated at $105^{\circ} \mathrm{C}$ for $10 \mathrm{~min}$ in advance. Ethyl acetate- formic acid-acetic acid-water 15: $1: 1: 1.5(\mathrm{v} / \mathrm{v})$ was utilized as a developer.

3 batches of samples $(5 \mu \mathrm{L})$ and standards were applied to the plates as $8 \mathrm{~mm}$ bands, $6 \mathrm{~mm}$ apart, using a CAMAG Linomat 5 sample applicator equipped with a $100 \mu \mathrm{L}$ syringe. The plates were developed in a $200 \mathrm{~mm} \times 100 \mathrm{~mm}$ twintrough chamber; the development distance was $18 \mathrm{~cm}$. The plates were removed from the chamber and dried. The densitometric determination was performed at $365 \mathrm{~nm}$ with a CAMAG TLC scanner 3 in absorbance mode. The slit dimensions were $10.00 \mathrm{~mm} \times 0.20 \mathrm{~mm}$ and the scanning speed was $50 \mathrm{~mm} \cdot \mathrm{s}^{-1}$. The source of radiation was a deuterium lamp emitting a continuous UV spectrum from $200 \mathrm{~nm}$ to $400 \mathrm{~nm}$.

2.4. Calibration Plots (Linearity). A working standard solution of rutin $0.88 \mathrm{mg} \cdot \mathrm{mL}^{-1}$ and rosmarinic acid $0.66 \mathrm{mg} \mathrm{mL}^{-1}$ were used to contrast calibration plots by applying 1.0, 2.0, 3.0, 4.0, $5.0 \mu \mathrm{L}$ each (corresponding to 270.7, 541.4, 812.1, $1082.8,1353.5 \mathrm{ng} /$ spot of rutin; 50.7, 101.4, 152.1, 202.8, $253.5 \mathrm{ng} /$ spot of rosmarinic acid) to a plate. Chromatographic plates were developed and scanned as described above. The responses of rutin and rosmarinic acid were linear functions of concentration over the range of 270.7-1353.5 ng/spot and $50.7-253.5 \mathrm{ng} / \mathrm{spot}$, separately; the equations of the calibration plots for rutin and rosmarinic acid were $Y=$ $1075.08+14232.21 X(r=0.9981), Y=393.37+50878.94 X$ $(r=0.9964)$. The chromatograms are shown in Figures 3, 4, and 5 .

\section{Results and Discussion}

3.1. Optimization of the Developer. The composition of the developer was optimized by testing different solvent systems of different polarity. The best resolution was obtained by use of ethyl acetate-formic acid-acetic acid- water $15: 1: 1: 1.5$ $(\mathrm{v} / \mathrm{v})$, and the obtained $R_{F}$ values were $0.31 \pm 0.03$ for rutin and $0.82 \pm 0.03$ for rosmarinic acid. 
TABLE 1: Results of recovery test of Rutin and Rosmarinic acid $(n=6)$.

\begin{tabular}{|c|c|c|c|c|c|c|c|}
\hline No. & $\begin{array}{l}\text { Amount of drug } \\
\text { taken }(\mathrm{g})\end{array}$ & $\begin{array}{l}\text { Amount of rutin } \\
\text { added }(\mathrm{mg})\end{array}$ & $\begin{array}{l}\text { Amount of rosmarinic } \\
\text { acid added (mg) }\end{array}$ & $\begin{array}{c}\text { Recovery } \\
\text { (rutin) }(\%)\end{array}$ & $\begin{array}{c}\text { Recovery (Rosmarinic } \\
\text { acid) (\%) }\end{array}$ & $\begin{array}{c}\text { RSD } \\
\text { (Rutin) (\%) }\end{array}$ & $\begin{array}{l}\text { RSD (rosmarinic } \\
\text { acid) (\%) } \\
\end{array}$ \\
\hline 1 & 1.0149 & 1.76 & 0.66 & 101.67 & 97.73 & \multirow{6}{*}{2.38} & \multirow{6}{*}{2.92} \\
\hline 2 & 1.0152 & 1.76 & 0.66 & 98.34 & 96.79 & & \\
\hline 3 & 1.0064 & 1.76 & 0.66 & 95.70 & 98.47 & & \\
\hline 4 & 1.0076 & 1.76 & 0.66 & 98.10 & 96.53 & & \\
\hline 5 & 1.0085 & 1.76 & 0.66 & 95.12 & 103.42 & & \\
\hline 6 & 1.0378 & 1.76 & 0.66 & 97.44 & 102.11 & & \\
\hline
\end{tabular}

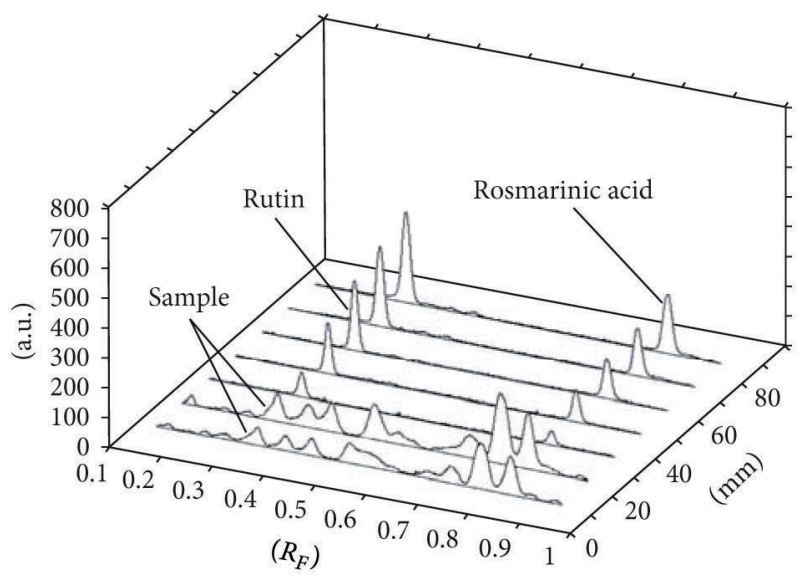

FIGURE 3: HPTLC chromatograms of rutin and rosmarinic acid mixture and ASMq samples.

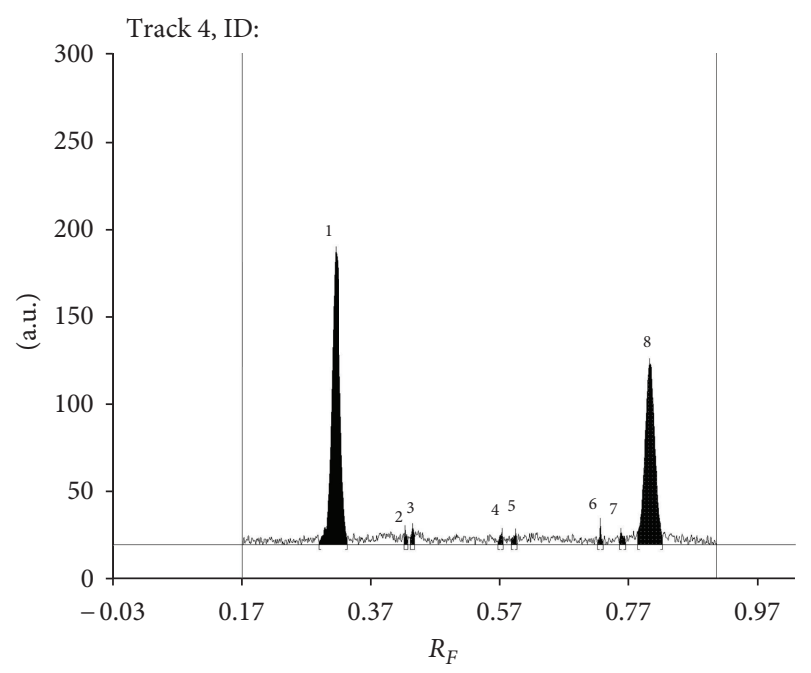

FIGURE 4: HPTLC chromatograms of standard samples.

3.2. Precision. The precision of the method was determined by analyzing standard solutions in triplicate at three concentrations on the same day and on different days for interday and intraday precision, respectively. Precision was expressed as RSD of the series of measurements.

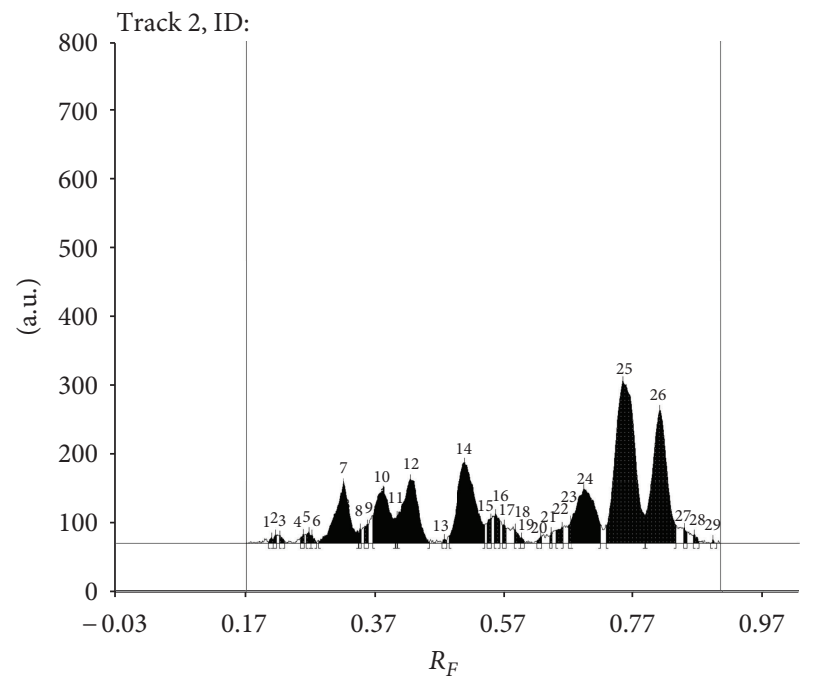

FIGURE 5: HPTLC chromatograms of rutin and rosmarinic acid mixture in ASMq.

The samples were checked repeatedly by measuring the five spots for the same concentration having same concentration of rutin and rosmarinic acid (1.354 mg per band for rutin and $0.254 \mathrm{mg}$ per band for rosmarinic acid mixed standards) applied on the same plate without changing the position of the plate. The relative standard deviations (RSDs) of intra-day were $2.0 \%$ and $3.0 \%$ for rutin and rosmarinic acid samples, respectively. The relative standard deviations (RSDs) of interday for the rutin and rosmarinic acid samples were $1.98 \%$ and $1.26 \%$, respectively.

3.3. Stability. Stability of the rutin and rosmarinic acid was assessed by use of quality-control samples (1.354 $\mathrm{mg}$ per band for rutin and $0.254 \mathrm{mg}$ for rosmarinic acid mixed standards); the measurement of the peak area and the peak height were checked at $1,2,4,8,24,48 \mathrm{~h}$. The RSDs for the rutin and rosmarinic acid samples are $1.83 \%$ and $1.56 \%$, respectively.

3.4. Recovery. Recovery of rutin and rosmarinic acid was determined by the standard addition method. Known amount of standards of rutin and rosmarinic acid $(1.67 \mathrm{mg}$ per band for rutin, $0.66 \mathrm{mg}$ per band for rosmarinic acid) were added to six prequantified samples. The amounts of 
TABLE 2: Quantification of rutin and rosmarinic acid in three batches of ASMq.

\begin{tabular}{lcc}
\hline ASMq no. & Rutin $(\mathrm{mg} / \mathrm{g})$ & Rosmarinic acid $(\mathrm{mg} / \mathrm{g})$ \\
\hline 201005 & $1.751 \pm 0.0027$ & $0.685 \pm 0.0023$ \\
201006 & $1.825 \pm 0.0031$ & $0.692 \pm 0.0021$ \\
201007 & $1.898 \pm 0.0029$ & $0.702 \pm 0.0027$ \\
\hline
\end{tabular}

rutin and rosmarinic acid were determined by measuring the peak areas and by fitting these values into the regression equation of the calibration plot. The results were shown in Table 1.

3.5. Quantification Limits. The limits of quantification (LOQ) were calculated by preparing solutions at six volumes $\left(0.5,1.0,1.5,2.0,2.5,3.0 \mu \mathrm{L}, 0.0027 \mathrm{ng} \cdot \mu \mathrm{L}^{-1}\right.$ for rutin and $0.0051 \mathrm{ng} \cdot \mu \mathrm{L}^{-1}$ for rosmarinic acid) in the lower range of linear regression curve. The LOQ were $4.1 \mathrm{ng} / \mathrm{spot}$ and $5.1 \mathrm{ng} / \mathrm{spot}$ for rutin and rosmarinic acid, respecticely.

3.6. Quantification of Rutin and Rosmarinic Acid in Samples. Amounts of rutin and rosmarinic acid in three batches of ASMq were shown in Table 2.

\section{Conclusion}

A rapid, precise, and simple HPTLC method has been established, which has good specificity, for simultaneous analysis of rutin and rosmarinic acid in ASMq for the first time. Use of silica gel $\mathrm{H}$ plants with ethyl acetate-formic acidacetic acid-water 15:1:1:1.5 (v/v) as developer enables good resolution with $R_{F}$ values of $0.31 \pm 0.03,0.82 \pm 0.03$ for rutin and rosmarinic acid, respectively.

Two color-developing agents were compared in this study, because of different principles. The air bleached the bands' color out after a while when alcoholic solution of sulfuric acid was used. It brought difficulties for stability of experiment. However, when aluminum chloride-ethanol solution (1.5\%) was used the bands' colors were clear and results were stable. The study offered basic research data for the establishment of quality standard of ASMq.

\section{Acknowledgment}

This work was supported by the Program for Changjiang Scholar and Innovative Team IRT0977.

\section{References}

[1] H. Upur, A. Yusup, A. Umar, and N. Moore, "Uighur traditional medicine syndrome of abnormal savda in men is associated with oxidative stress, which can be improved by munziq and mushil of abnormal savda," Therapie, vol. 59, no. 4, pp. 483-484, 2004.

[2] Y. Abdiryim, I. Guzalnur, R. Nurjan, A. Ainiwaer, and U. Halmurat, "Effects of immune regulation of abnormal savda munziq granular on immune suppressed mice," Science \& Technology Review, vol. 28, no. 3, pp. 82-86, 2010.

[3] A. Ablimit, A. Yusup, and H. Upur, "Protective effects of abnormal savda munziq and mushil on damage of DNA," Pharmacology and Clinics of Chinese Materia Medica, vol. 16, no. 3, pp. 34-36, 2000.

[4] A. Yusup, H. Upur, A. Umar, and N. Moore, "Protective effects of munziq and mushil of abnormal savda to mitochondrial oxidative damage," Fundamental and Clinical Pharmacology, vol. 18, no. 4, pp. 471-476, 2004.

[5] A. Yusup, H. Upur, I. Baudrimont et al., "Cytotoxicity of abnormal savda munziq aqueous extract in human hepatoma (HepG2) cells," Fundamental and Clinical Pharmacology, vol. 19, no. 4, pp. 465-472, 2005.

[6] http://www.tcmtcm.com/Rutin/.

[7] F. C. Stinzinga, D. Kammerera, A. Schiebera, H. Adamab, O. G. Nacoulmab, and R. Carlea, "Betacyanins and phenolic compounds from amaranthus spinosus $\mathrm{L}$. and boerhavia erecta L.," Zeitschrift fur Naturforschung C, vol. 59, pp. 1-8, 2004.

[8] K. Ashok Kumar, S. Ramachandra Shetty, and L. Narsu, "HPTLC method development and validation for determination of rutin in flavanoidal fraction of Hibiscus Micranthus Linn," E-Journal of Chemistry, vol. 8, no. 3, pp. 1444-1450, 2011.

[9] http://www.chemblink.com/products/20283-92-5C.htm.

[10] http://www.phytochemicals.info/phytochemicals/rosmarinicacid.php.

[11] X. B. Jia, G. M. Liu, L. Feng, Y. Chen, D. S. Jia, and F. Shi, "Determination of rutin and quercetin in Prunella vulgaris by HPLC," West China Journal of Pharmaceutical Science, vol. 25, no. 1, pp. 70-71, 2010.

[12] H. Wang and Z. Q. Zhang, "Medicine property variation in different proportional combinations of scutellariae radix and prepared pinellia tuber through determination leaching quantity of baicalin by HPLC," Chinese Journal of Experiment Traditional Medical Formulae, no. 17, pp. 116-118, 2011.

[13] A. Yusup, G. Imam, N. Rozi, A. Aikemu, and H. Upur, "Effects of immune regulation of abnormal savda munziq granular on immune suppressed mice," Science \& Technology Review, vol. 1, pp. 39-41, 2010.

[14] I. Guzalnur, W. Pu, G. P. Xue, J. G. Xing, and X. Y. Li, "Alcohol extraction technology of abnormal savda munziq granular," Science \& Technology Review, vol. 28, no. 15, pp. 79-82, 2010. 

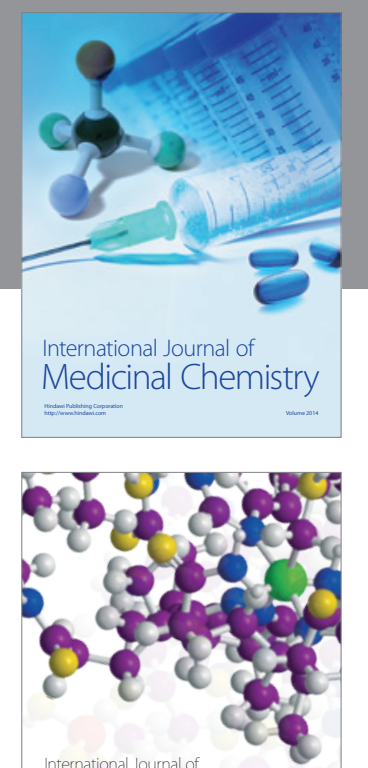

\section{Carbohydrate} Chemistry

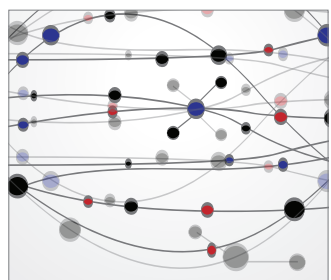

The Scientific World Journal
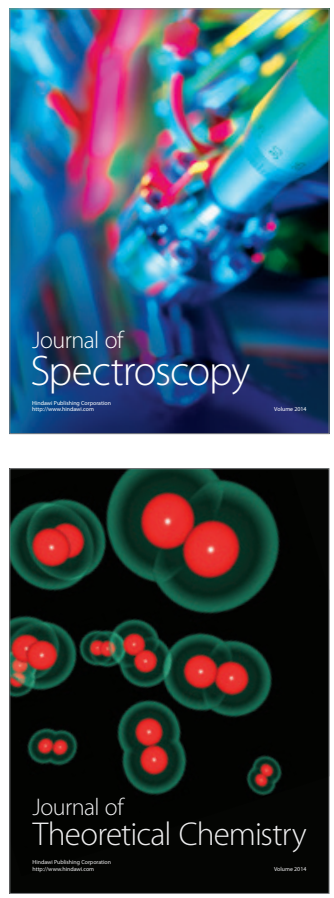
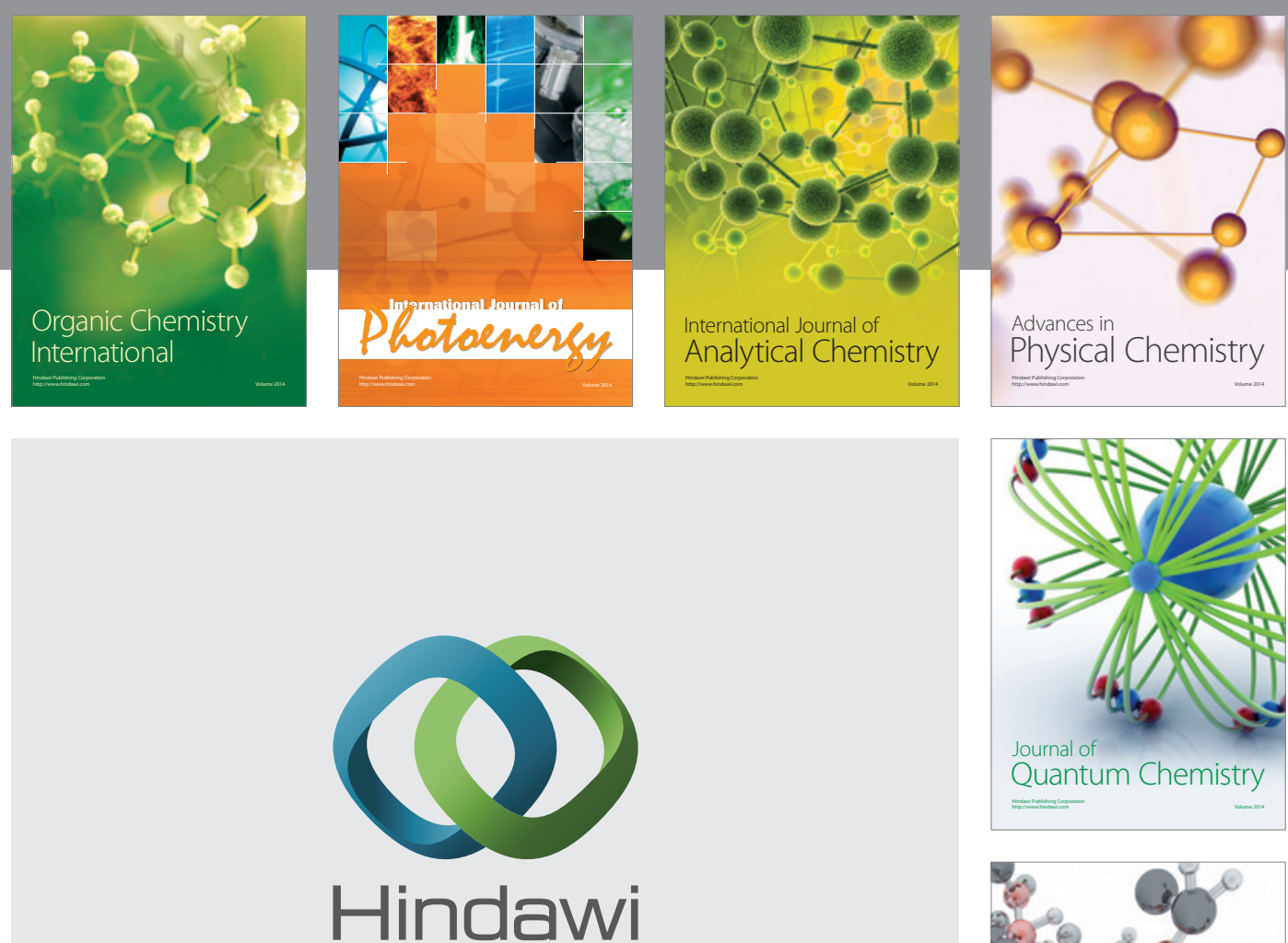

Submit your manuscripts at

http://www.hindawi.com

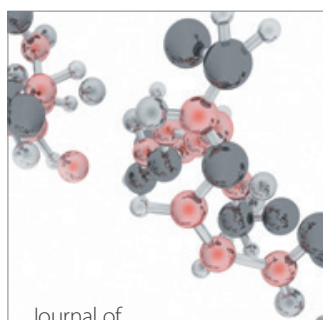

Analytical Methods

in Chemistry

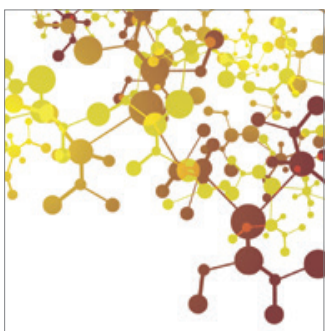

Journal of

Applied Chemistry

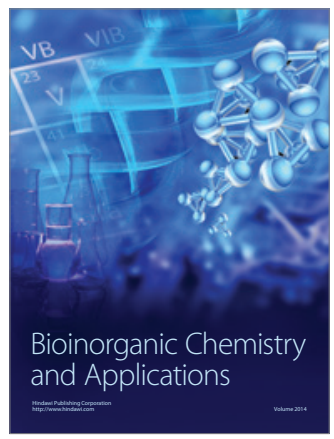

Inorganic Chemistry
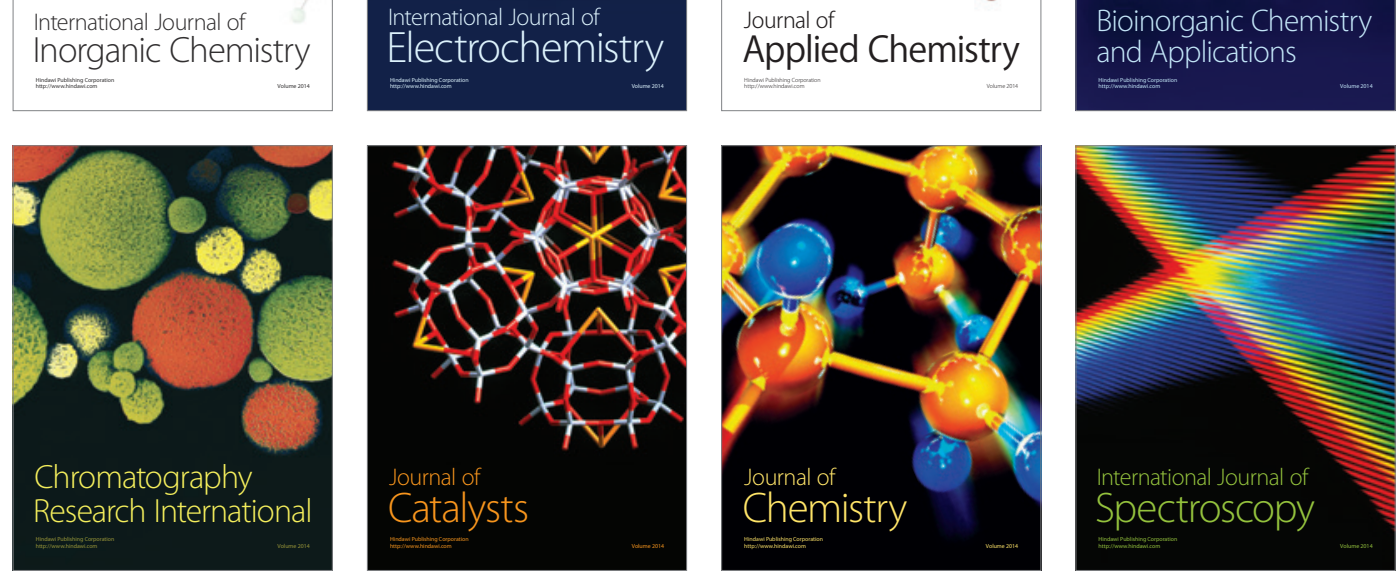